\title{
Erratum to: Pathophysiology of atypical femoral fractures and osteonecrosis of the jaw
}

\section{J. Compston}

Published online: 26 October 2011

(C) International Osteoporosis Foundation and National Osteoporosis Foundation 2011

\section{Erratum to: Osteoporos Int}

DOI 10.1007/s00198-011-1804-x

In the subsection Atypical femoral fractures / Pathophysiology / Suppression of bone turnover, the last word of the first paragraph should have been "hypoparathyroidism", not "hyperparathyroidism". The sentence concerned should read "In osteosclerotic bone diseases due to decreased bone resorption, however, AFFs have not been reported, nor have they been described in other conditions associated with low bone turnover such as hypothyroidism or hypoparathyroidism." The author sincerely regrets any confusion that may have been caused.

The online version of the original article can be found at http://dx.doi. org/10.1007/s00198-011-1804-x.

J. Compston $(\bowtie)$

Cambridge University Hospitals NHS Foundation Trust,

Cambridge CB2 0QQ, UK

e-mail: jec1001@cam.ac.uk 